\title{
SARCOCYSTIS JAMAICENSIS N. SP., FROM RED-TAILED HAWKS (BUTEO JAMAICENSIS) DEFINITIVE HOST AND IFN- $\gamma$ GENE KNOCKOUT MICE AS EXPERIMENTAL INTERMEDIATE HOST
}

\author{
S. K. Verma, A. Rosypal von Dohlen*, J. D. Mowerył, D. Scottł, B. M. Rosenthal, J. P. Dubey, and D. S. Lindsay§ \\ United States Department of Agriculture, Agricultural Research Service, Beltsville Agricultural Research Center, Animal Parasitic Diseases Laboratory, Building \\ 1001, Beltsville, Maryland 20705-2350. Correspondence should be sent to J. P. Dubey at: Jitender.Dubey@ars.usda.gov
}

\begin{abstract}
Here, we report a new species of Sarcocystis with red-tailed hawk (RTH, Buteo jamaicensis) as the natural definitive host and IFN- $\gamma$ gene knockout (KO) mice as an experimental intermediate host in which sarcocysts form in muscle. Two RTHs submitted to the Carolina Raptor Center, Huntersville, North Carolina, were euthanized because they could not be rehabilitated and released. Fully sporulated $12.5 \times 9.9-\mu \mathrm{m}$ sized sporocysts were found in intestinal scrapings of both hawks. Sporocysts were orally fed to laboratory-reared outbred Swiss Webster mice (SW, Mus musculus) and also to KO mice. The sporocysts were infective for KO mice but not for SW mice. All SW mice remained asymptomatic, and neither schizonts nor sarcocysts were found in any SW mice euthanized on days $54,77,103(\mathrm{n}=2)$ or 137 post-inoculation (PI). The KO mice developed neurological signs and were necropsied between 52 to 68 days PI. Schizonts/merozoites were found in all KO mice euthanized on days 52, $55(\mathrm{n}=3), 59,61(\mathrm{n}=2), 66$, and $68 \mathrm{PI}$ and they were confined to the brain. The predominant lesion was meningoencephalitis characterized by perivascular cuffs, granulomas, and necrosis of the neural tissue. The schizonts/merozoites were located in neural tissue and were apparently extravascular. Brain homogenates from infected $\mathrm{KO}$ mice were infective to $\mathrm{KO}$ mice by subcutaneous inoculation and when seeded on to CV-1 cells. Microscopic sarcocysts were found in skeletal muscles of 5 of $8 \mathrm{KO}$ mice euthanized between 55-61 days PI. Only a few sarcocysts were detected. Sarcocysts were microscopic, up to $3.5 \mathrm{~mm}$ long. When viewed with light microscopy, the sarcocyst wall appeared thin $(<1 \mu \mathrm{m}$ thick $)$ and smooth. By transmission electron microscopy, the sarcocyst wall classified as "type 1j" (new designation). Molecular characterization using $18 S$ rRNA, $28 S$ rRNA, ITS-1, and cox1 genes revealed a close relationship with Sarcocystis microti and Sarcocystis glareoli; both species infect birds as definitive hosts. The parasite in the present study was biologically and molecularly different from species so far described in RTHs and we therefore propose a new species name, Sarcocystis jamaicensis n. sp.
\end{abstract}

Species of Sarcocystis have a 2-host life cycle with an asexual development in the extra-intestinal tissues of an intermediate host (often an herbivore) and sexual reproduction in the intestine of the definitive host (a carnivore). The definitive host becomes infected by ingesting tissues of the intermediate hosts containing mature sarcocysts. Bradyzoites released from these sarcocysts penetrate into the lamina propria of the small intestine and undergo fertilization to form oocysts within a day. Oocysts sporulate in situ and sporulated oocysts or sporocysts released from oocysts are excreted in feces. The intermediate host becomes infected by ingesting food or water contaminated with sporocysts. Sporozoites released from sporocysts initiate asexual multiplication, first as schizonts and then as sarcocysts. Mature sarcocysts contain hundreds of bradyzoites. In general, bradyzoites are infectious only for the definitive hosts and oocysts are infectious only for the intermediate hosts. Occasionally, some hosts can act as both intermediate and definitive hosts, but usually not for the same species of Sarcocystis (Dubey et al., 2016).

\footnotetext{
Received 13 January 2017; revised 15 June 2017; accepted 21 June 2017. * Department of Natural Sciences and Mathematics, Johnson C. Smith University, Charlotte, North Carolina 28216.

$\dagger$ United States Department of Agriculture, Agricultural Research Service, Beltsville Agricultural Research Center, Electron and Confocal Microscopy Unit, Building 12, Beltsville, Maryland 20705.

\& Carolina Raptor Center, 6000 Sample Road, Huntersville, North Carolina 28078.

$\S$ Department of Biomedical Sciences and Pathobiology, College of Veterinary Medicine, Faculty of Health Sciences, Virginia Tech, Blacksburg, Virginia 24061.

DOI: $10.1645 / 17-10$
}

Sarcocystis infection is common in the skeletal muscles (Lindsay and Blagburn, 1989) and intestines (Yabsley et al., 2009) of raptors in the United States. Lindsay and Blagburn (1999) found sarcocysts in muscles of 20 of 34 (58.8\%) red-tailed hawks (RTH, Buteo jamaicensis) that were necropsied at a center in Alabama and Yabsley et al. (2009) found sporocysts in feces/ intestines of 39 of $57(68.4 \%)$ of RTHs in Georgia. Thus, the RTH is a common host for Sarcocystis species. Of all Sarcocystis infections reported, RTHs have been established as a definitive host for S. microti (Lindsay et al., 1987, 1992; Lindsay and Blagburn, 1989; Upton and McKown, 1992). Prairie voles (Microtus ochrogaster) orally inoculated with sporocysts derived from 1 of 6 RTHs became infected and developed characteristic lobulated cysts in their brains but not in muscles (Lindsay et al., 1992; Upton and McKown, 1992). Yabsley et al. (2009) characterized partial sequence of $18 S \mathrm{SRNA}$ using DNA extracted from sporocysts from the feces of an RTH designated as Sarcocystis sp. (EU810395) but did not assign it to any of the Sarcocystis species. The present study describes in vitro and in vivo isolation of a Sarcocystis species from the feces of 2 naturally infected RTHs and molecular analysis using $18 S \mathrm{rRNA}, 28 \mathrm{~S}$ rRNA, ITS-1, and coxl genes.

\section{MATERIALS AND METHODS}

\section{Naturally infected red-tailed hawks}

Two RTHs (no. 18678 and no. 19013) were admitted to the Carolina Raptor Center, Huntersville, North Carolina. Male RTH no. 18678 was collected from Salisbury, Rowan County, North Carolina. It had an injured elbow. Female, juvenile RTH 
TABLE I. Bioassay summary of sporocysts collected from the intestinal contents of red-tailed hawks (RTH) in IFN- $\gamma$ gene knockout (KO) and Swiss Webster $(\mathrm{SW})$ mice. ND = not done; DPI = day post-inoculation; TEM = transmission electron microscopy.

\begin{tabular}{|c|c|c|c|c|c|c|c|c|}
\hline Host & Dose & Mouse & $\begin{array}{c}\text { Necropsy } \\
\text { (DPI) }\end{array}$ & $\begin{array}{l}\text { Clinical } \\
\text { signs* }\end{array}$ & $\begin{array}{l}\text { Sub passage } \\
\text { in KO mouse }\end{array}$ & $\begin{array}{c}\text { Cell } \\
\text { culture }\end{array}$ & \multicolumn{2}{|r|}{ Remarks } \\
\hline & & $641 \mathrm{KO}$ & 61 & Yes & Yes & Yes & Brain & Skeletal muscle \\
\hline & & $642 \mathrm{KO}$ & 55 & Yes & Yes & Yes & Brain & Skeletal and heart muscles \\
\hline & 30,000 & $368 \mathrm{KO}$ & 52 & Yes & ND & Yes & Brain & Negative \\
\hline & & $365 \mathrm{SW}$ & 147 & No & ND & ND & Negative & Negative \\
\hline \multirow[t]{4}{*}{ Sub passage } & $640 \mathrm{KO}$ brain & $149 \mathrm{KO}$ & 59 & Yes & ND & Yes & Brain & Negative \\
\hline & tissue & $150 \mathrm{KO}$ & 105 & Yes & ND & Yes & Brain & Negative \\
\hline & $641 \mathrm{KO}$ brain & $172 \mathrm{KO}$ & 71 & Yes & ND & Yes & Brain & Negative \\
\hline & tissue & $173 \mathrm{KO}$ & 176 & No & ND & ND & Negative & Negative \\
\hline \multirow[t]{3}{*}{ RTH no. 19013} & 32,000 & $840 \mathrm{KO}$ & 59 & Yes & & & Brain & Skeletal muscle \\
\hline & & $841 \mathrm{KO}$ & 55 & Yes & & & Brain & Skeletal muscle (TEM) \\
\hline & & $748 \mathrm{SW}$ & 103 & No & & & Negative & Negative \\
\hline
\end{tabular}

* Weak, neurological signs.

no. 19013 was collected from Charlotte, Mecklenburg County, North Carolina. It had blunt force trauma with a left humeral fracture and meningeal bleeding in the right side of the cranium from its right eye to its right cerebrum-cerebellar junction. Both birds were euthanized because they could not be rehabilitated and released. After necropsy, sporocysts were collected separately from the intestinal scraping of both birds as described previously (Lindsay et al., 2017).

\section{Experimental infection of mice}

Sporocysts were sent to the Animal Parasitic Diseases Laboratory (APDL), U.S. Department of Agriculture, Beltsville, Maryland for further experimentation. At APDL, sporocysts were inoculated orally into Swiss Webster (SW) mice (Mus musculus) and IFN- $\gamma$ gene knockout (KO) mice. The mice were euthanized after various time intervals (Table I). Complete necropsies were performed and portions of heart, lung, spleen, tongue, eye, brain, kidney, liver, intestine, muscles, and other organs were fixed in $10 \%$ buffered neutral formalin. Fixed tissue samples were cut into sections $(2.5 \times 0.7 \mathrm{~cm})$, placed in cassettes, embedded in paraffin, and sectioned $5 \mu \mathrm{m}$ thick. Tissue sections were stained with hematoxylin and eosin (H\&E) and observed using light microscopy. Remaining carcasses of SW mice were homogenized in a blender, digested in acid pepsin, and aliquots of digests were examined microscopically for bradyzoites as described previously (Dubey et al., 2016).

Additionally, a paraffin block of skeletal muscle that had sarcocysts identified by $\mathrm{H} \& \mathrm{E}$ staining was deparaffinized and processed for transmission electron microscopy (TEM). Sections stained with uranyl acetate and lead citrate were examined and imaged at $80 \mathrm{kV}$ with a Hitachi HT-7700 transmission electron microscope (Hitachi High Technologies America Inc., Dallas, Texas).

\section{Cell culture}

African green monkey kidney (CV-1) cells (ATCC CCL-70, Manassas, Virginia) were grown in $25-\mathrm{cm}^{2}$ cell culture flasks in Roswell Park Memorial Institute (RPMI) 1640 cell culture medium (Mediatech, Inc., Manassas, Virginia) containing 100 IU penicillin $/ \mathrm{ml}, 100 \mu \mathrm{g} / \mathrm{ml}$ streptomycin $/ \mathrm{ml}$, and $10 \%$ (v/v) fetal bovine serum (FBS). Cells were maintained in the same medium except the concentration of FBS was $2 \%$. Living cell cultures were examined in $25-\mathrm{cm}^{2}$ flasks using an inverted microscope equipped with phase-contrast optics (Zeiss Invertoskope, Thornwood, New York) for 60 days post-inoculation (PI) of parasites. Cell culture medium was replenished once or twice a week PI based on these observations.

Infected mouse brain (no. $368 \mathrm{KO}$ ) was placed in $3 \mathrm{ml}$ of Hank's buffered salt solution (HBSS) and passed through a sterile, 10-ml syringe into a $15-\mathrm{ml}$ screw cap centrifuge tube. Sterile, 2-mm glass beads were added up to about $0.5 \mathrm{ml}$ in the test tube and the sample vortexed for about $10 \mathrm{sec}$. The samples were examined for the presence of merozoites using light microscopy on the unstained sample. The sample (about $0.5 \mathrm{ml} / \mathrm{flask}$ ) was inoculated onto each of 5 monolayers of CV-1 cells in $25-\mathrm{cm}^{2}$ flasks. The inoculums were removed $2 \mathrm{hr}$ later when $5 \mathrm{ml}$ of maintenance medium was added. Flasks were examined daily for 21 days and then every other day thereafter.

Once merozoites were observed in inoculated cultures, the media was used to infect other flasks of $\mathrm{CV}-1$ cells to keep the cultures growing. This was done at various times to obtain parasites for developmental studies. Parasite development was examined using CV-1 cells grown on sterile, 22- $\mathrm{mm}^{2}$ glass coverslips containing $\mathrm{CV}-1$ cells, each inoculated with merozoites in maintenance medium. The number of merozoites was not determined. The inoculum was removed $24 \mathrm{hr}$ PI and replaced with maintenance medium. Coverslips were removed at 1-8 days $\mathrm{PI}$ and processed for light microscopic examination after staining 
with Giemsa. The 22- $\mathrm{mm}^{2}$ coverslips were fixed in $10 \%(\mathrm{v} / \mathrm{v})$ buffered formalin solution for $10 \mathrm{~min}$ and then post-fixed in $100 \%$ methanol for $10 \mathrm{~min}$, air dried, stained with Giemsa for $1 \mathrm{hr}$, and mounted on glass slides using Permount ${ }^{\mathrm{TM}}$ (Fisher Scientific Company, Fair Lawn, New Jersey) for microscopic examination.

\section{DNA extractions and PCR amplification}

Three individual sarcocysts isolated mechanically from $\mathrm{KO}$ mouse no. 640 (Table I) under a light microscope were directly transferred into animal tissue lysis (ATL) buffer (Qiagen, Inc., Valencia, California). Genomic DNA from both individual sarcocysts and cell-cultured merozoites were extracted using DNeasy Blood and Tissue Kit (Qiagen, Inc.) according to manufacturer instructions. DNA quantification and quality were determined by Thermo Scientific NanoDrop Lite Spectrophotometer (Thermo Scientific, Waltham, Massachusetts). Molecular characterization was done by amplification and sequencing of 3 regions of the nuclear ribosomal DNA units; $18 S \mathrm{rRNA}$, internal transcribed spacer-1 (ITS-1) and $28 S r R N A$, and a mitochondrial cytochrome $\mathrm{c}$ oxidase subunit 1 ( $\operatorname{cox} 1$ ) locus following the procedures as previously described (Gjerde and Josefsen, 2015). The PCR amplifications were performed in 50- $\mu$ l total reaction volume containing $20 \mathrm{ng}$ template DNA, $10 \mathrm{pmol}$ of each primer, and $1 \times$ Taq PCR Master Mix Kit (Qiagen, Inc.). The thermal cycler (Veriti ${ }^{\circledR}$ Thermal Cycler, Applied Biosystems, Foster City, California) conditions were set at initial denaturation at $95 \mathrm{C}$ for $10 \mathrm{~min}$; 40 cycles of amplification (95 C for $45 \mathrm{sec}, 52-56 \mathrm{C}$ for 45 $\mathrm{sec}$, and $72 \mathrm{C}$ for $1 \mathrm{~min}$ ), and final extension at $72 \mathrm{C}$ for $10 \mathrm{~min}$. Both the positive (DNA from Sarcocystis neurona isolate) and the negative $\left(\mathrm{H}_{2} \mathrm{O}\right)$ controls were included in all the batches, respectively. The amplified PCR products were run on $2.5 \%(\mathrm{w} /$ v) agarose gel with ethidium bromide stain and visualized by using the Gel Logic 212 Imaging Systems (Eastman Kodak Company, Rochester, New York).

\section{DNA sequencing and phylogenetic analysis}

The PCR amplicons of $18 S$ rRNA, $28 S$ rRNA, ITS-1, and cox 1 were excised from the gel and purified using QIAquick Gel Extraction (Qiagen, Inc.) according to the manufacturer's recommendation. The purified PCR products were sent to Macrogen Corporation (Rockville, Maryland) for direct sequencing using the same primer pair used in amplification to obtain both reads. The resulting sequences were imported, read, edited manually if necessary, and analyzed using the software Geneious version 9.0.4 (Biomatters Ltd., Auckland, New Zealand). New sequences were compared with other sequences deposited in National Center for Biotechnology Information (NCBI) GenBank by BLASTn analysis (https://blast.ncbi.nlm.nih.gov/Blast. cgi?PAGE_TYPE=BlastSearch) to detect intraspecies and interspecies variation on these DNA regions.

Phylogenetic trees based on $28 S$ rRNA sequences were constructed using new sequences obtained from Sarcocystis jamaicensis n. sp. from RTHs. Input sequences were the $28 \mathrm{~S}$ $r R N A$ regions of different Sarcocystis species and related taxons retrieved from NCBI GenBank. One hundred bootstrap replicates of the phylogenetic relationships among these sequences were reconstructed under the criterion of maximum likelihood using PhyML as implemented in Geneious version 9.0.4 (Guindon et al., 2010). The HKY85 model of nucleotide substitution was used, estimating the transition/transversion ratio and the gamma distribution parameter to model rate variation among sites. No sites were presumed to be invariant. The complete deletion method was used for ambiguous/missing data, and topologies were searched using the nearest neighbor interchange method.

\section{RESULTS}

\section{Sporocysts}

Fully sporulated sporocysts were found in the intestinal scrapings of both RTHs. They measured $12.5 \times 9.9 \mu \mathrm{m}(11.2$ $13.7 \times 8.8-10.9, \mathrm{n}=15)$. Each sporocyst contained 4 elongated $7.5-8.5 \times 2-2.3 \mu \mathrm{m}$ sporozoites and a residual body. A Stieda body was not present in sporocysts.

\section{Sarcocysts}

Sarcocysts were rare. One sarcocyst was detected in unstained squash of leg muscles of KO mice no. 640; it was $3.5 \mathrm{~mm}$ long and $33 \mu \mathrm{m}$ wide (Fig. 1A). Five sarcocysts were found in histological sections of muscles of $3 \mathrm{KO}$ mice (Table I); 4 sarcocysts in skeletal muscle and 1 in the heart (Fig. 1B-D). In histological sections sarcocysts were up to $80 \mu \mathrm{m}$ long and up to $65 \mu \mathrm{m}$ wide. The sarcocyst wall was $<1 \mu \mathrm{m}$ thick and appeared smooth, wavy, without projections.

Three sarcocysts from a paraffin block were examined by TEM. The parasitophorous vacuolar membrane (pvm) of the sarcocyst wall was wavy, lined by thin electron dense layer (edl), and had villar protrusions (vp). The vp were stump-shaped, close together, distributed at uneven distances, varied in sizes, and appeared to have stalk at the bottom and expanded tip. The vp lacked microtubules and electron dense granules. The pvm invaginated toward the sarcocyst interior. The ground substance layer (gs) beneath the pvm was smooth, up to $1 \mu \mathrm{m}$ thick, and continued into the interior of the sarcocyst as septa (Fig. 2).

All SW mice remained asymptomatic. Neither schizogonic stages nor sarcocysts were found in any SW mice euthanized on days 54, 77, $103(\mathrm{n}=2)$, and $137 \mathrm{PI}$; bradyzoites were not found in the pepsin digest of muscles of any SW mice.

\section{Schizonts}

All inoculated KO mice developed neurological signs and were necropsied between 52 to 68 days PI. Schizonts/merozoites were confined to the brain (Table I). The predominant lesion was meningoencephalitis characterized by perivascular cuffs, granulomas, and necrosis of neural tissue. The schizonts and merozoites were located in neural tissues and appeared extravascular (Fig. $3 \mathrm{~A}-\mathrm{C}$ ). Brain homogenates from infected $\mathrm{KO}$ mice were infective to $\mathrm{KO}$ mice and $\mathrm{CV}-1$ cells (Table I).

\section{In vitro cultivation}

Flasks of CV-1 cells inoculated with brain homogenate from each mouse contained visible schizonts and merozoites at 9 days PI. Merozoites from the isolate from mouse (no. 150) were used to examine development in CV-1 cell on Giemsa stained coverslips (Fig. 3D-H). Merozoites penetrated CV-1 cells and were developmental stages located next to the host cell nucleus (Fig. $3 \mathrm{E}$ ). Merozoites were $7 \times 2 \mu \mathrm{m}$ and contained a centrally located nucleus. The merozoites increased in size and retained their 


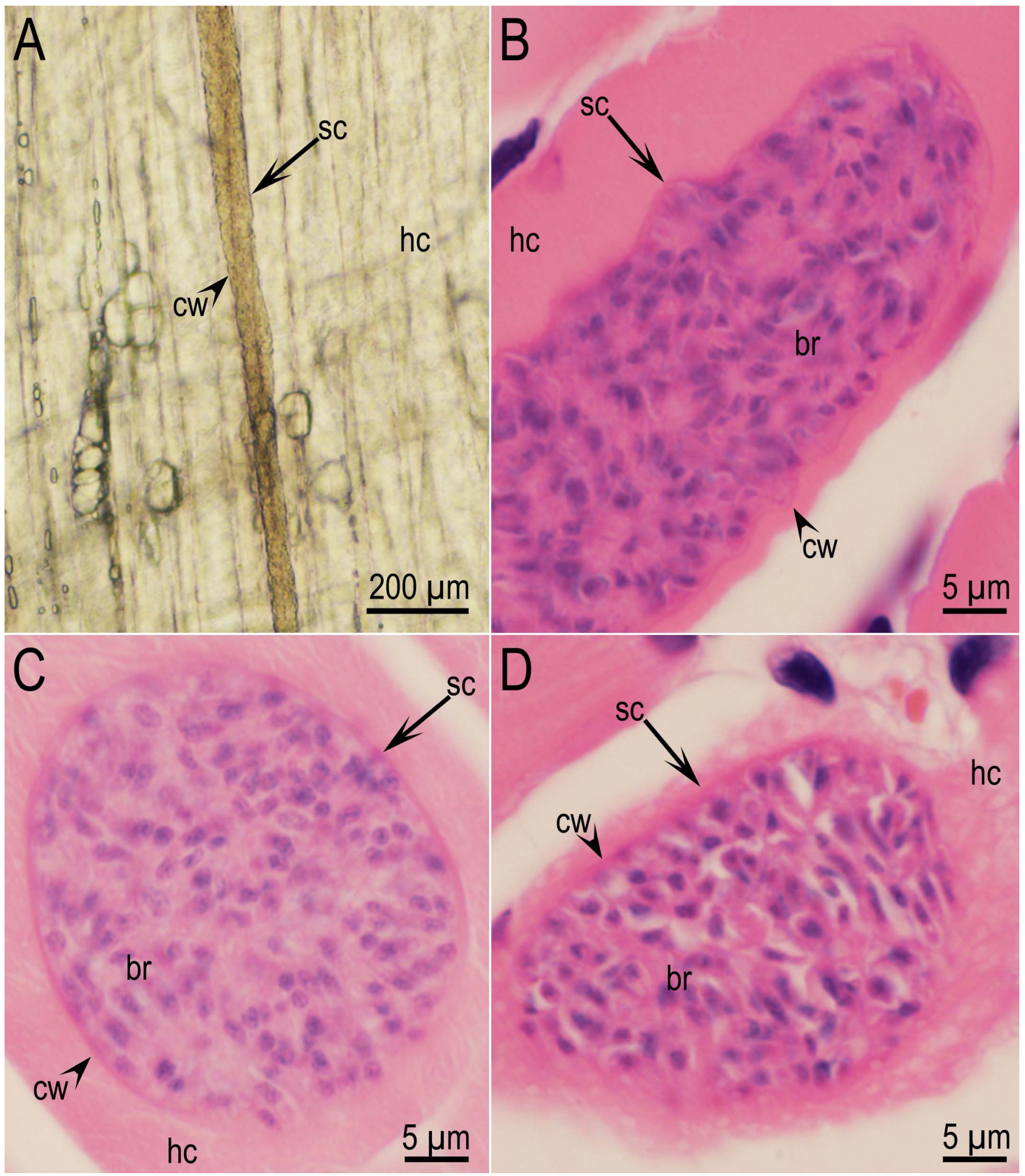

FIGURE 1. Sarcocysts of Sarcocystis jamaicensis n. sp. in experimentally infected knockout (KO) mice. Sarcocyst (sc), cyst wall (cw), host cell (hc), and bradyzoites (br). (A) Unstained sarcocyst in squash of semitendinosus muscle, 61 days post-inoculation (PI). (B-D) Histological sections stained with hematoxylin and eosin. (B, C) Sarcocyst in leg muscle, 55 and 59 days PI. Note thin sarcocyst wall, undulating surface, and without any visible protrusions. (D) Sarcocyst in heart muscle, 55 days PI 

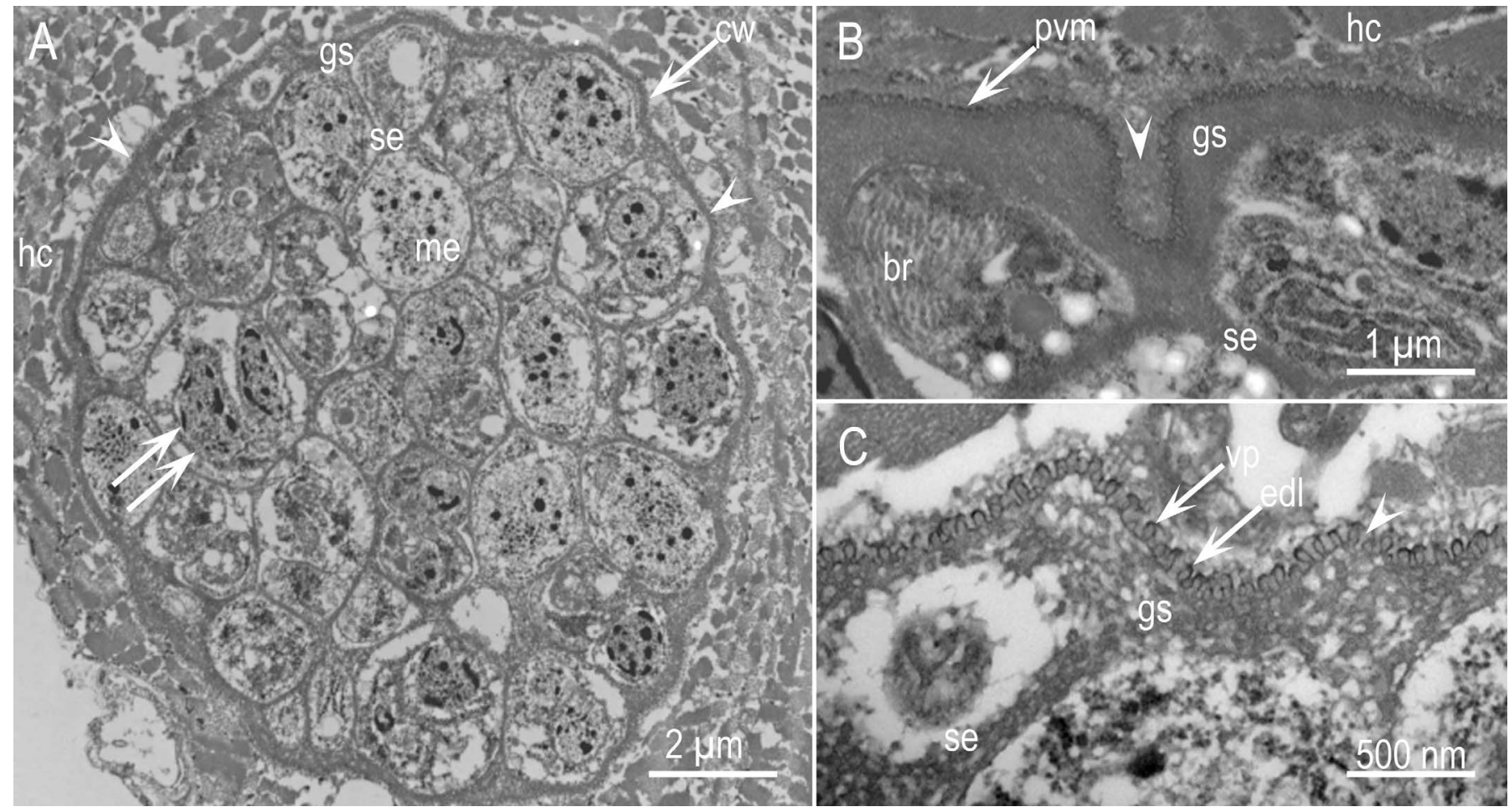

FIGURE 2. Transmission electron microscopy of Sarcocystis jamaicensis n. sp. sarcocysts in semitendinosus muscle, knockout mouse no. 841,55 days post-inoculation. Host cell (hc), villar protrusion (vp), ground substance layer (gs), and bradyzoites (br). (A) The sarcocyst has undulating surface. The gs is smooth and continued in the interior of the sarcocyst as septa (se). (B) Note parasitophorous vacuolar membrane (pvm) is wavy. (C) Villar protrusions (vp) are lined by very thin electron dense layer (edl), stump-shaped, close together, distributed at uneven distances, varied in sizes, and without microtubules or granules.

merozoite shape. A mixture of merozoites and developing schizonts appeared to be in the same host cell (Fig. 3D). The nucleus increased in size and the number of nucleoli increased as the nucleus enlarged and began to develop lobes. Merozoites formed on the surface of schizonts around nuclei that became incorporated as they were produced (Fig. 3F, G). Merozoites developing in a rosette pattern were often observed (Fig. $3 \mathrm{H}$ ).

\section{PCR and DNA analysis}

DNA sequencing of amplicons resulted in the unambiguous sequences of $18 S$ rRNA (1,633 bp), $28 S$ rRNA (1,526 bp), ITS-1 (1,007 bp), and coxl (1,072 bp). These sequences were submitted to NCBI GenBank with accession numbers KY994649 (18S $r R N A)$, KY994650 (28S rRNA), KY994651 (ITS-1), and KY994652 (coxl) and designated as Sarcocystis jamaicensis n. sp. Analysis of $18 S r R N A$ sequence (KY994649) obtained from $S$. jamaicensis confirmed its membership among the genus Sarcocystis and indicated an especially close relationship and $\geq 99 \%$ sequences identity to other parasites in this genus, which employs birds as their hosts; Sarcocystis lari (JQ733508) from the great black-backed gull (Larus marinus), Sarcocystis turdusi (JF975681) from the blackbird (Turdus merula), Sarcocystis sp. ex Phalacrocorax carbo (JQ733511) from great cormorant (Phalacrocorax carbo), Sarcocystis sp. ex Columba livia (GQ245670) from racing pigeon (Columba livia), Sarcocystis sp. ex Anser albifrons (EU502869) from white-fronted geese (Anser albifrons), Sarcocystis corvusi (JN256117) from jackdaw (Corvus monedula),
Sarcocystis columbae (HM125054) from the woodpigeon (Columba palumbus), Sarcocystis cornixi (EU553478) from the hooded crow (Corvus cornix), and many other species of Sarcocystis.

The partial 28S rRNA sequence of S. jamaicensis (KY994650) shared $99 \%$ identity with both sequences of Sarcocystis (Frenkelia) glareoli (AF044251) and Sarcocystis (Frenkelia) microti (AF044252) followed by $98 \%$ identity with Sarcocystis sp. ex Columba livia (KF601312), Sarcocystis arctica (KF601312, KX022105-KX022107), Sarcocystis lutrae (KM657771, KM657772), Sarcocystis sp. ex Anser albifrons (EF079886), S. turdusi (JF975682), S. columbae (HM125053), Sarcocystis sp. ex Phalacrocorax carbo (JQ733512), and many other species of Sarcocystis.

The ITS-1 sequence of S. jamaicensis (KY994651) shared the highest identity (78\%) with Sarcocystis canis (DQ176645) isolate from the polar bear (Ursus maritimus), Sarcocystis calchasi (KC733715) from the long-billed corella (Cacatua tenuirostris), and $74-75 \%$ identity with $S$. lutrae (KM657773-KM657805) from the Eurasian otter (Lutra lutra), Sarcocystis wobeseri from the European herring gull (Larus argentatus) (HM159421), the mallard or wild duck (Anas platyrhynchos) (JN256121), and the barnacle goose (Branta leucopsis) (GU475111) followed by Sarcocystis sp. from the European badger (Meles meles) (KX431307), Sarcocystis sp. ex Phalacrocorax carbo from the great cormorant (Phalacrocorax carbo) (JQ733513), Sarcocystis sp. ex Columba livia from the racing pigeon (Columba livia dom.) (FJ232948), S. columbae from the common wood pigeon (Columba palumbus) (HM125052, GU253885), S. calchasi from the Eurasian collared dove (Strepto- 


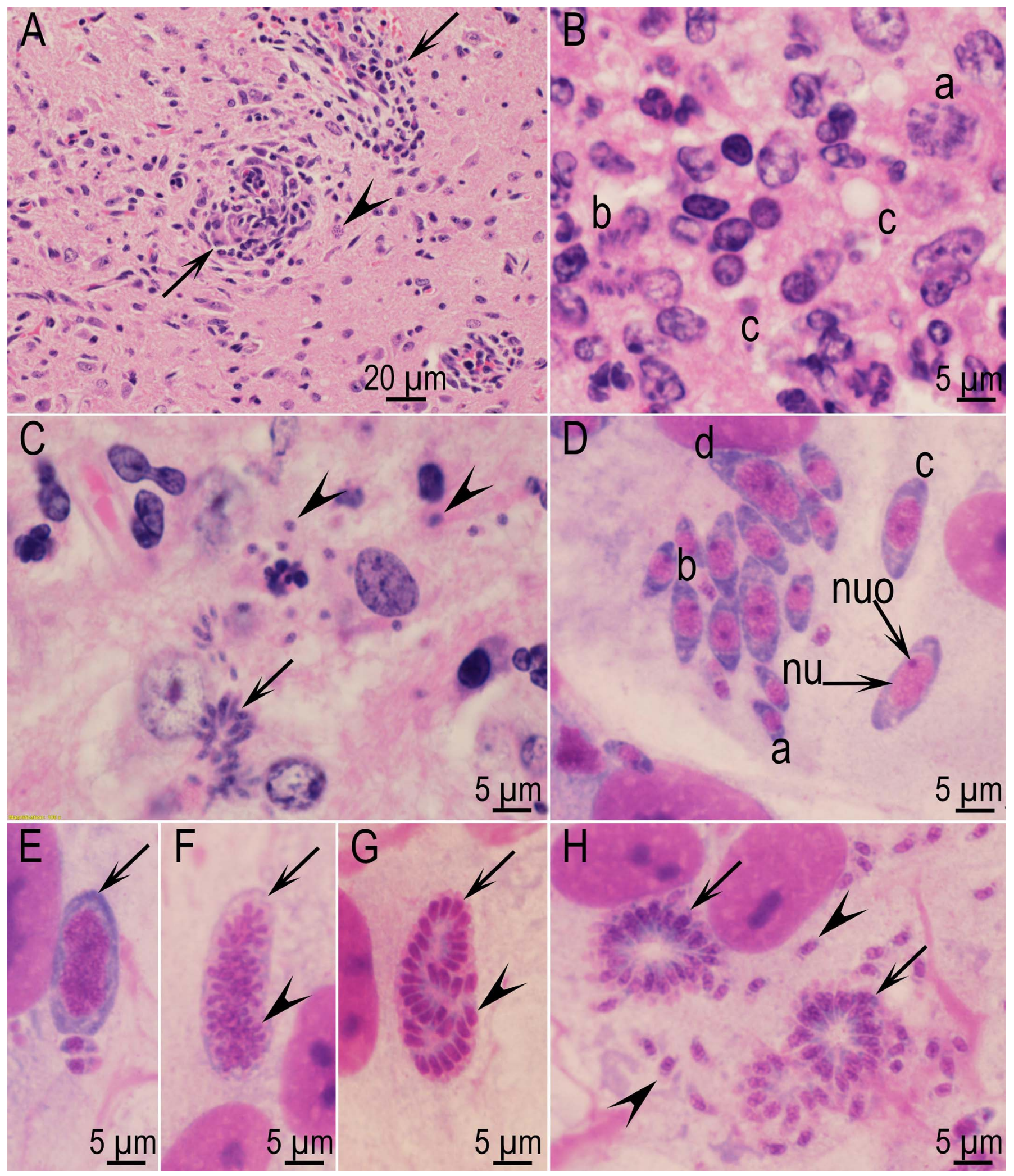

FIGURE 3. Schizogonic stages of Sarcocystis jamaicensis n. sp. (A-C) In vivo stages in brains of experimentally infected knockout (KO) mice inoculated with sporocysts. Hematoxylin and eosin stain. (D-H) In vitro stages in CV-1 cells. Giemsa stain. (A) Severe perivasculitis (arrows)-KO mouse no. 814, 66 days post-inoculation (PI). (B) Developing schizonts (a,b) and individual merozoites in neural parenchyma (c), KO mouse no. 642 , day 55 PI. (C) Two mature schizonts (arrow) and free merozoites (arrowheads), KO mouse no. 814, day 66 PI. (D) Early stages of developing schizonts, in presumed order of development $(\mathrm{a}-\mathrm{d}$ ). Note a large, undivided nucleus (nu) with a prominent nucleolus (nuo). (E) Immature schizont (arrow) with 2lobed nucleus and 2 free merozoites in adjoining area. (F) Immature schizont (arrow) with highly lobulated nucleus (arrowhead). (G) Formation of merozoites (arrowhead). (H) Rosettes of merozoites in schizonts and individual merozoites (arrowheads). 


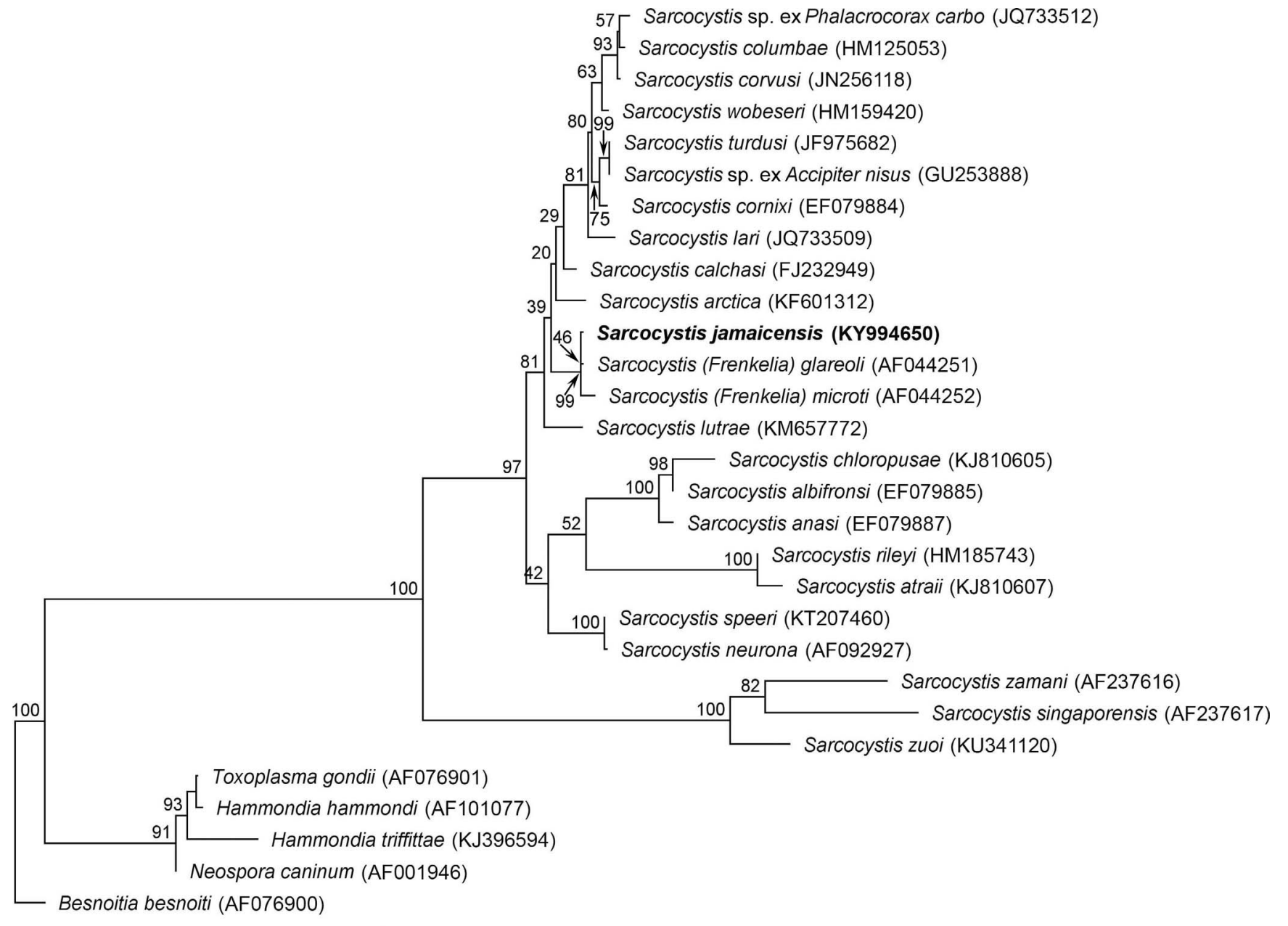

0.09

Figure 4. Phylogenetic tree based on $28 S r R N A$ sequences. Input sequences were the $28 S r R N A$ regions of various species of Sarcocystis and related taxons retrieved from National Center for Biotechnology Information (NCBI) GenBank and a new $28 S$ rRNA sequence obtained from Sarcocystis jamaicensis $\mathrm{n}$. sp. Accession numbers of sequences were given in parentheses following the species name. One hundred bootstrap replicates of the phylogenetic relationships among these sequences were reconstructed under the criterion of maximum likelihood using PhyML as implemented in Geneious version 9.0.4. Sarcocystis jamaicensis n. sp. showed close relationship with Sarcocystis microti and Sarcocystis glareoli and less bootstrap support with many species of Sarcocystis that use birds as their definitive and intermediate hosts.

pelia decaocto) (KT945021, KT945022), and many other species of Sarcocystis.

The partial coxl sequence of $S$. jamaicensis (KY994652) shared 99\% identity with S. lutrae (KM657808, KF601326), S. turdusi (KT588511-KT588518), S. arctica (KX022112-KX022115, KF601318-KF601321), and Sarcocystis speeri (KT207461) and 97-98\% identity with S. rileyi (KT184389, KJ396582), Sarcocystis sp. ex Pantherophis alleghaniensis (KU891603), S. calchasi (KU220952), and S. neurona (KF854272).

\section{Phylogenetic analysis}

In phylogenetic trees based on $28 S$ rRNA sequences, $S$. jamaicensis clustered consistently in a clade with $S$. microti and $S$. glareoli and had less bootstrap support with many species of Sarcocystis that use birds as hosts (Fig. 4). The RTH (Buteo jamaicensis) and the common buzzard (Buteo buteo) are known definitive hosts for $S$. microti. Sarcocystis glareoli uses the common buzzard as definitive hosts, and this parasite has not been reported from North America (Dubey et al., 2016). There are no available $I T S-1$ sequences of $S$. glareoli and $S$. microti.

\section{DESCRIPTION}

\section{Sarcocystis jamaicensis $\mathbf{n}$. sp.}

(Figs. 1-4)

Diagnosis: Sporocysts in the intestine of Red-tailed hawks, 12.5 $\times 9.9(11.2-13.7 \times 8.8-10.9, \mathrm{n}=15) \mu \mathrm{m}$. Sporocysts were orally infective to KO mice but not to SW mice. Schizonts/merozoites in brain. Sarcocysts up to $33 \mu \mathrm{m}$ wide and up to $3.5 \mathrm{~mm}$ long with "type 1j" (new designation) villar protrusions (vp) on the sarcocyst wall; vp stump-shaped, close together, distributed at uneven distances, varied in sizes, lacked microtubules and electron dense granules.

\section{Taxonomic summary}

Type definitive host: Red-tailed hawks (Buteo jamaicensis). 
Natural intermediate host: Unknown.

Experimental intermediate host: IFN- $\gamma$ gene knockout mouse. Type locality: North Carolina, United States of America.

Other localities: Unknown.

Etymology: Species named after the species name of the definitive host; Red-tailed hawks (Buteo jamaicensis).

Specimens deposited: Hematoxylin and eosin-stained histologic slides from the IFN- $\gamma$ gene knockout (KO) mouse; no. D8526 (containing sarcocysts in skeletal muscle, USNM 1445754), D 10007 (containing schizonts in brain, USNM 1445755), and tissue culture-slide-coverslip Giemsa-stained preparation showing schizonts and merozoites (USNM 1445756) have been catalogued at the National Parasite collection housed at the Smithsonian Institution, National Museum of Natural History, Department of Invertebrate Zoology (USNM).

Sequences deposited: Sequences deposited in NCBI GenBank with accession numbers KY994649 (18S rRNA), KY994650 (28S $r R N A)$, KY994651 (ITS-1), and KY994652 (coxl).

\section{Remarks}

Sarcocystis species are generally host-specific for the intermediate host, especially those using rodents as intermediate hosts (Dubey et al., 2016). The ultrastructure of the sarcocyst wall is a useful taxonomic criterion for differentiating Sarcocystis species within a given host. The sarcocyst wall of the species in the present study is structurally distinct from other species described. Dubey et al. (2016) proposed 42 types of sarcocyst walls with many subdivisions within some of the wall types. By light microscopy, sarcocysts were grouped as thinwalled $(<1 \mu \mathrm{m})$ or thick-walled $(>2 \mu \mathrm{m})$. The type 1 sarcocyst wall is thin and has small blebs on the wall; it was subdivided into 8 subtypes $(1 \mathrm{a}-1 \mathrm{~h})$ depending on the villar protrusions (Dubey et al., 2016). To this description another wall type was designated "type 1i" for the recently reported new species of Sarcocystis, Sarcocystis pantherophisi (Verma et al., 2017). To this description we now have added another new "type $1 \mathrm{j}$ " for the Sarcocystis species S. jamaicensis in the present study. The new "type $1 \mathrm{j}$ " is defined as follows: The sarcocyst wall had a wavy, undulating parasitophorous vacuolar membrane (pvm); the undulations were at irregular distances. The vp were stumpshaped, close together, distributed at uneven distances, varied in sizes, and appeared to have stalk at the bottom and expanded tip. The vp lacked microtubules and electron dense granules. The pvm invaginated toward the sarcocyst interior. The ground substance layer (gs) beneath the pvm was smooth, up to $1 \mu \mathrm{m}$ thick.

Although the ultrastructure of the sarcocysts in the present study was preliminary, it is likely to help in finding the natural intermediate host(s) for S. jamaicensis. For TEM in the present study, formalin fixed, paraffinized embedded muscle was used because of the rarity of sarcocysts in muscles of the KO mice inoculated with sporocysts from RTHs. The sarcocyst wall was preserved better than were the bradyzoites. Further studies are needed to fully characterize Sarcocystis infections of raptors.

\section{DISCUSSION}

There is a considerable confusion in the literature concerning the nomenclature of Sarcocystis microti. Findlay and Middleton
(1934) found protozoan cysts in the brain of the short-tailed field vole (Microtus agrestis) from Wales, U.K. and they called it Toxoplasma microti. The cysts were large and lobulated and confined to the brain. Frenkel (1953) found a similar parasite in a vole (Microtus pennsylvanicus) in Montana, and he referred to it as "M organism" because it could not be assigned to any genus at that time (Frenkel, 1953). A similar parasite found in bank vole (Clethrionomys glareolus) was called Toxoplasma glareolus (Erhardová, 1955). Biocca (1968) erected a new genus, Frenkelia, and transferred T. microti to Frenkelia microti. When the life cycles of Sarcocystis species were discovered in the 1970s, it became clear that some Sarcocystis species also form sarcocysts in brain in addition to muscles, undermining the basis that location in the brain was the major feature distinguishing Frenkelia from Sarcocystis (reviewed in Dubey et al., 1989). The buzzards ( $B$. buteo and $B$. borealis) were found as definitive hosts for the 2 species of Frenkelia with tissue cysts in the brains of voles (Rommel and Krampitz, 1975). Many authors using the molecular data reached the same conclusion, that Frenkelia should be synonymized as a junior synonym to Sarcocystis (reviewed in Dubey et al., 2016).

Dubey (1983) named Sarcocystis microti for the sarcocysts he found in meadow vole (Microtus pennsylvanicus) from Montana. Its sarcocysts are microscopic and have a thick, striated cyst wall. Modrý et al. (2004) recognized the taxonomic conflict and proposed a new name combination for $S$. microti from the meadow vole as Sarcocystis jaypeedubeyi (Modrý et al., 2004). Thus, the correct name for the parasite originally called $T$. microti, and subsequently F. microti, is Sarcocystis microti (Findlay and Middleton, 1934; Modrý et al., 2004). Yabsley et al. (2009) incorrectly referred to Sarcocystis (Frenkelia) microti as $S$. jaypeedubeyi in their report on RTHs from Georgia.

Of the 2 species of Frenkelia formally accepted as valid, $F$. microti (S. microti), and F. glareoli (S. glareoli), only S. microti has been found in the United States. These 2 species are morphologically distinguishable by their cysts; S. glareoli cysts are microscopic and unlobulated whereas $S$. microti cysts are macroscopic and lobulated, and cysts are confined to the brain (Dubey et al., 2016). Sarcocystis (Frenkelia) microti-like cysts have been reported as single cases in a chinchilla (Dubey et al., 2000a) and laboratory rat (Hayden et al., 1976) from the United States and in a porcupine (Kennedy and Frelier, 1986) and a muskrat (Karstad, 1963) from Canada. In all of these 4 cases, cysts were lobulated and confined to the brain.

The parasite found in the present study is distinct from $S$. microti; the only species characterized from the RTH based on molecular, biologic, and molecular characteristics. As stated earlier, Yabsley et al. (2009) characterized a partial sequence of $18 S$ rRNA using DNA extracted from sporocysts from the feces of a RTH designated as Sarcocystis sp. RTH378-04 (EU810395) but did not assign it to any of the Sarcocystis species. Multiple sequence alignment of the $18 S r R N A$ region $(783 \mathrm{bp})$ established that Sarcocystis sp. RTH378-04 (EU810395) is distinguishable from the parasite in the present report (S. jamaicensis) by 4 single nucleotide polymorphisms (SNPs); at nucleotide position 91 (Sarcocystis sp. RTH378-04 has an A; S. jamaicensis has a T), at nucleotide position 136 (Sarcocystis sp. RTH378-04 has an A; S. jamaicensis has a $\mathrm{T}$ ) in reference to sites in the published sequence (EU810395). The other possible nucleotide differences between these 2 sequences, $\mathrm{R}$ (A or $\mathrm{G}$ ) at position 139, and M (A or C) at 
position 340 in $S$. jamaicensis sequence, indicate uncertainty or a potential of 2 different nucleotides at these particular sites. In the present study, the molecular data based on DNA derived from 2 stages of the parasite (sarcocysts from muscle of $\mathrm{KO}$ mice, and schizonts/merozoites from cell culture) were identical, supporting the view that both stages belonged to $S$. jamaicensis; no attempt was made to extract DNA from sporocysts.

The parasite in the present study resembles Sarcocystis neurona with respect to sporocyst infectivity, neurological signs (e.g., head-tilt, circling), and schizonts/merozoites localized in brain. The KO mice have proved very useful in understanding the biology of $S$. neurona, which causes fatal encephalomyelitis in horses (called EPM) and many other hosts and is a major cause of mortality in sea otters (Dubey et al., 2015). The encephalitis in $\mathrm{KO}$ mice mimics the natural disease. The $\mathrm{KO}$ mice are considered an aberrant host for $S$. neurona because only schizonts are produced; sarcocysts are absent. In this respect, finding of sarcocysts in KO mice orally inoculated with sporocysts from RTHs feces is noteworthy and might assist in finding the natural intermediate host for S. jamaicensis. Not all species of Sarcocystis are transmissible to $\mathrm{KO}$ mice and thus passage through $\mathrm{KO}$ can help to distinguish Sarcocystis species in a given host, and caution should be used while comparing different species. For example, opossums (Didelphis spp.) are definitive hosts for 4 or more species that are molecularly related but biologically distinct. Of these, $S$. falcatula and $S$. lindsayi are infective for birds but not $\mathrm{KO}$ mice, and $S$. speeri and $S$. neurona are infective for KO mice and not birds (reviewed in Dubey et al., 2016). Additionally, $S$. speeri forms sarcocysts in KO mice but $S$. neurona does not. Furthermore, merozoites of $S$. speeri are not infective for $\mathrm{KO}$ mice whereas merozoites of $S$. neurona are infective to $\mathrm{KO}$ mice by pareneral routes. In this respect, $S$. jamaicensis differed from both $S$. speeri and $S$. neurona because its merozoites were infective to KO mice with production of sarcocysts. However, we did not test infectivity of its sporocysts to birds.

Development of $S$. jamaicensis in vitro is similar to that of $S$. neurona and $S$. speeri isolates from opossums that infect $\mathrm{KO}$ mice but not birds (Dubey and Lindsay, 1998, 1999; Lindsay et al., 1999; Dubey et al., 2000b). Development is also similar to that reported for $S$. falcatula, $S$. lindsayi, and $S$. falcatula Argentinalike isolates from opossums that infect birds but not $\mathrm{KO}$ mice (Lindsay et al., 1999, Dubey et al., 2000c, 2001). Developing schizonts of $S$. falcatula, S. lindsayi, and S. falcatula Argentinalike produce merozoites that are more spherical in shape than the developing schizonts of $S$. jamaicensis in this study and those of $S$. neurona and S. speeri (Lindsay et al., 1999; Dubey et al., 2000b) that usually retain their merozoite shape. Developing schizonts of Sarcocystis sp. ex Accipiter cooperii from a naturally infected Cooper's hawk (Accipiter cooperii) are similar to those of $S$. jamaicensis; however, the merozoites of Sarcocystis sp. ex $A$. cooperii develop a sausage shape (Lindsay et al., 2017) that is different from the merozoite shape of schizonts of $S$. jamaicensis, $S$. neurona, and S. speeri (Lindsay et al., 1999; Dubey et al., 2000c). The infectivity of Sarcocystis sp. ex A. cooperii for KO mice and birds has not been reported (Lindsay et al., 2017).

\section{ACKNOWLEDGMENTS}

This work was supported in part by grant no. 1505407 from the National Science Foundation Historically Black Colleges and
Universities Undergraduate Program to A.R.V.D. and an Internal Research Competition (IRC) grant from the VirginiaMaryland College of Veterinary Medicine to D.S.L. Mention of trade names or commercial products in this publication is solely for the purpose of providing specific information and does not imply recommendation or endorsement by the U.S. Department of Agriculture (USDA); USDA is an equal opportunity provider and employer.

\section{LITERATURE CITED}

BioccA, E. 1968. Class Toxoplasmatea: Critical review and proposal of the new name Frenkelia gen. n. for M-organism. Parassitologia 10: 89-98.

Dubey, J. P. 1983. Sarcocystis montanaensis and S. microti sp. n. from the meadow vole (Microtus pennsylvanicus). Proceedings of the Helminthological Society of Washington 50: 318-324.

Dubey, J. P., R. Calero-Bernal, B. M. Rosenthal, C. A. Speer, AND R. FAYER. 2016. Sarcocystosis of animals and humans, 2nd ed. CRC Press, Boca Raton, Florida, 481 p.

Dubey, J. P., T. R. Clark, and D. Yantist. 2000a. Frenkelia microti infection in a chinchilla (Chinchilla laniger) in the United States. Journal of Parasitology 86: 1149-1150.

Dubey, J. P., D. K. Howe, M. Furr, W. J. Saville, A. E. Marsh, S. M. Reed, AND M. E. Grigg. 2015. An update on Sarcocystis neurona infections in animals and equine protozoal myeloencephalitis (EPM). Veterinary Parasitology 209: $1-42$.

Dubey, J. P., AND D. S. LindsAy. 1998. Isolation in immunodeficient mice of Sarcocystis neurona from opossum (Didelphis virginiana) faeces and its differentiation from Sarcocystis falcatula. International Journal for Parasitology 29: 18231828.

Dubey, J. P., And D. S. Lindsay. 1999. Sarcocystis speeri n. sp (Protozon: Sarcocystdae) from the opossum (Didelphis virginiana). Journal of Parasitology 85: 903-909.

Dubey, J. P., D. S. Lindsay, L. Venturini, and C. Venturini. 2000c. Characterization of Sarcocystis falcatula isolates from the Argentinian opossum, Didelphis albiventris. Journal of Eukaryotic Microbiology 47: 260-263.

Dubey, J. P., B. M. Rosenthal, and C. A. Speer. 2001. Sarcocystis lindsayi n. sp. (Protozoa: Sarcocystidae) from the South American opossum, Didelphis albiventris from Brazil. Journal of Eukaryotic Microbiology 48: 595-603.

Dubey, J. P., C. A. Speer, and R. Fayer. 1989. Sarcocystosis of animals and man. CRC Press, Boca Raton, Florida, 215 p.

Dubey, J. P., C. A. Speer, And D. S. Lindsay. 2000b. In vitro cultivation of schizonts of Sarcocystis speeri Dubey and Lindsay, 1999. Journal of Parasitology 86: 671-678.

ERHARdovÁ, B. 1955. Nachweis toxoplasmaahnlicher parasiten bei der rotelmaus Clethrionomys glareolus. Folia Biologica 1: 381-382.

Findlay, G. M., And A. D. Middleton. 1934. Epidemic disease among voles (Microtus) with special reference to Toxoplasma. Journal of Animal Ecology 3: 150-160.

FRENKEL, J. K. 1953. Infections with organisms resembling Toxoplasma, together with the description of a new organism: Besnoitia jellisoni. Atti del VI Congresso Internazionale di Microbiologia 5: 426-434. 
Gjerde, B., And T. D. Josefsen. 2015. Molecular characterisation of Sarcocystis lutrae n. sp. and Toxoplasma gondii from the musculature of two Eurasian otters (Lutra lutra) in Norway. Parasitology Research 114: 873-886.

Guindon, S., J. F. Dufayard, V. Lefort, M. Anisimova, W. HordiJk, and O. Gascuel. 2010. New algorithms and methods to estimate maximum-likelihood phylogenies: Assessing the performance of PhyML 3.0. Systematic Biology 59: $307-321$.

Hayden, D. W., N. W. King, and A. S. K. Murthy. 1976. Spontaneous Frenkelia infection in a laboratory-reared rat. Veterinary Pathology 13: 337-342.

Karstad, L. 1963. Toxoplasma microti (the M-organism) in the muskrat (Ondatra zibethica). Canadian Veterinary Journal 4: 249-251.

Kennedy, M. J., And P. F. Frelier. 1986. Frenkelia sp. from the brain of a porcupine (Erethizon dorsatum) from Alberta, Canada. Journal of Wildlife Diseases 22: 112-114.

Lindsay, D. S., S. I. Ambrus, and B. L. Blagburn. 1987. Frenkelia sp.-like infection in the small intestine of a redtailed hawk. Journal of Wildlife Diseases 23: 677-679.

Lindsay, D. S., AND B. L. Blagburn. 1989. Caryospora uptoni and Frenkelia sp.-like coccidial infections in red-tailed hawks (Buteo borealis). Journal of Wildlife Diseases 25: 407-409.

Lindsay, D. S., ANd B. L. Blagburn. 1999. Prevalence of encysted apicomplexans in muscles of raptors. Veterinary Parasitology 80: $341-344$

Lindsay, D. S., J. P. Dubey, K. M. Horton, and D. D. Bowman. 1999. Development of Sarcocystis falcatula in cell cultures demonstrates that it is different from Sarcocystis neurona. Parasitology 118: 227-233.

Lindsay, D. S., S. J. Upton, M. Toivio-Kinnucan, R. D. McKown, And B. L. Blagburn. 1992. Ultrastructure of
Frenkelia microti in prairie voles inoculated with sporocysts from red-tailed hawks. Journal of the Helminthological Society of Washington 59: 170-176.

Lindsay, D. S., S. K. Verma, D. Scott, J. P. Dubey, and A. R. VON DOHLENL. 2017. Isolation, molecular characterization, and in vitro schizogonic development of Sarcocystis sp. ex Accipiter cooperii from a naturally infected Cooper's hawk (Accipiter cooperii). Parasitology International 66: 106-111.

Modrý, D., J. VotÝPKA, AND M. SvobodovÁ. 2004. Note on the taxonomy of Frenkelia microti (Findlay \& Middleton, 1934) (Apicomplexa: Sarcocystidae). Systematic Parasitology 58: 185-187.

Rommel, M., and H. E. Krampitz. 1975. Beiträge zum Lebenszyklus der Frenkelien. I. Die Identität von Isospora buteonis aus dem Mäusebussard mit einer Frenkelienart ( $F$. clethrionomyobuteonis spec. n.) aus der Rötelmaus. Berliner und Münchener Tierärztliche Wochenschrift 88: 338-340.

Upton, S. J., And R. D. McKown. 1992. The red-tailed hawk, Buteo jamaicensis, a native definitive host of Frenkelia microti (Apicomplexa) in North America. Journal of Wildlife Diseases 28: 85-90.

Verma, S. K. D. S. Lindsay, J. D. Mowery, B. M. Rosenthal, AND J. P. DubEy. 2017. Sarcocystis pantherophisi n. sp., from eastern rat snakes (Pantherophis alleghaniensis) definitive hosts and interferon gamma gene knockout mice as experimental intermediate hosts. Journal of Parasitology 103: $547-554$

Yabsley, M. J., A. E. Ellis, D. E. Stallknecht, and E. W. Howerth. 2009. Characterization of Sarcocystis from four species of hawks from Georgia, USA. Journal of Parasitology 95: $256-259$. 